\title{
PUBLICATIONS OF AESTHETIC INTEREST
}

Abell, Catharine and Katerina Bantinaki, eds. Philosophical Perspectives on Depiction. Oxford: Oxford University Press, 2010.

Anderberg, Thomas. Den stora konstsvindeln. Stockholm: Atlas, 2010.

Andersen, Frits: Det mørke kontinent? Afrikabilleder i europceiske fortcellinger om Congo. Aarhus: Aarhus University Press, 2011.

Andersen, Tore Rye. Den nye amerikanske roman. Aarhus: Aarhus University Press, 2011.

Baggesgaard, Mads Anders and Jakob Ladegaard, eds. Confronting Universalities: Aesthetics and Politics under the Sign of Globalisation. Aarhus: Aarhus University Press, 2011.

Benediktsson, Karl and Katrín A. Lund, eds. Conversations with Landscape. Ashgate Publishing, 2010.

Berkesand, Peter et al., eds. Codex and Code: Aesthetics, Language and Politics in an Age of Digital Media. Linköping: Linköping University Electronic Press, 2010.

Bolt, Mikkel. En anden verden: Små kritiske epistler om de seneste årtiers antikapitalistiske satsninger $i$ kunst og politik og forsøgene på at udradere dem. Copenhagen: Nebula, 2011.

Bolt Rasmussen, Mikkel and Jacob Wamberg, eds. Totalitarian Art and Modernity. Aarhus: Aarhus University Press, 2010.

Bolt Rasmussen, Mikkel and Jakob Jakobsen, eds. Expect Anything Fear Nothing: The Situationist Movement in Scandinavia and Esewhere. Copenhagen and New York: Nebula \& Autonomedia, 2011.

Borg, Alexandra. En vildmark av sten: Stockholm i litteraturen 1897-1916. Litteraturvetenskapliga institutionen, Uppsala universitet, PhD Diss. Stockholm: Stockholmia förlag 2011.

Brynjarsdóttir, Eyja M., ed. "Aesthetics" Hugur, Vol. 22. Reykjavík: Icelandic Philosophical Society, 2010.

Carroll, Noël. Art in Three Dimensions. Oxford: Oxford University Press, 2010.

Dagsdóttir, Úlfhildur. Sceborgin: Stefnumót líkama og tcekni [The Cyborg: Juncture of Body and Technology]. Reykjavík: Háskólaútgáfan [Universty of Iceland Press], 2011.

Enge, Håvard. Music Reading Poetry. Hans Zender's Musical Reception of Hölderlin. Institutt for musikkvitenskap, Universitetet i Oslo, PhD Diss., 2011.

Eväsoja, Minna, ed. Itämainen estetiikka [Oriental Aesthetics]. Helsinki: Gaudeamus Helsinki University Press, 2011. 
Frank, Søren: Salman Rushdie: A Deleuzian Reading. Copenhagen: Museum Tusculanum, 2011.

Gottlieb, Lennart: Modernisme og maleri. Aarhus: Aarhus University Press, 2011.

Heikkilä, Martta, ed. Taidekritiikin perusteet [The Foundations of Art Criticism]. Helsinki: Gaudeamus Helsinki University Press, 2011.

Heinänen, Seija, Pauline von Bonsdorff, and Virpi Kaukio, eds. Tunne maisema. Helsinki: Maahenki, 2011.

Hellemo, Geir. Øyet som ser. Oslo: Solum forlag, 2011.

Hestholm, Marion. Fragments, Flights, and Forms: Montage as a Constructive Principle in Twentieth-Century Music. Institutt for musikkvitenskap, Universitetet i Oslo, PhD Diss., 2011.

Hämäläinen, Nora. A Literary Turn: Rethinking the Roles of Generalization and Theory in Anglo-American Moral Philosophy. Helsinki: Philosophical Studies from the University of Helsinki, 2009.

Jalving, Camilla: Vork som handling: Performativitet, kunst og metode. Copenhagen: Museum Tusculanum, 2011.

Kaplan, Brett Ashley. Landscapes of Holocaust Postmemory. New York and London: Routledge, 2011.

Karlsen, Ole, ed. Poesie og bildekunst: En antologi. Oslo: Fagbokforlaget, 2011.

Kemp, Susanne: Appeller: Astetik i det 2o. århundredes danske lyrik. Odense: Syddansk Universitetsforlag, 2010.

Kjeldsen, Jens E.. Tale med billeder - tegne med ord. Oslo: Spartacus, 2011.

Lamarque, Peter. Work and Object: Explorations in the Metaphysics of Art. Oxford: Oxford University Press, 2010.

Larsen, Peter Stein: Drømme og dialoger: To poetiske traditioner omkring år 2000. Odense: Syddansk Universitetsforlag, 2010.

Lund, Jacob: Erindringens aestetik: Essays. Aarhus: Forlaget Klim, 2011.

Lyotard, Jean-François. Discourse, Figure. Translated by Antony Hudek and Mary Lydon. Minneapolis and London: University of Minnesota Press, 2011.

Madsen, Carsten \& Stefan Kjerkegaard, eds. Musikken, verset, poesien: Tekster af og om Stéphane Mallarmé. Aarhus: Aarhus University Press, 2010.

Mai, Anne-Marie: Hvor litteraturen finder sted: Moderne Tider; 1900-2010. Copenhagen: Gyldendal, 2011.

Małecki, Wojciech. Embodying Pragmatism: Richard Shusterman's Philosophy and Literary Theory. Frankfurt am Main: Peter Lang, 2010.

Mattsson, Helena and Sven-Olov Wallenstein, eds. Swedish Modernism: Architecture, Consumption and the Welfare State. London: Black Dog, 2010.

Meyer, Siri. Visuell makt. Bilder, blikk og betraktere. Oslo: Universitetsforlaget, 2010. 
Naukkarinen, Ossi. Arjen estetiikka [Everyday Aesthetics]. Helsinki and Espoo: Aalto-yliopisto Taideteollinen korkeakoulu, 2011.

Olsson, Nils. Konsten att sätta texter $i$ verket: Gertrude Stein, Arne Sand och litteraturens (o)befintliga specificitet. Institutionen för litteratur, idéhistoria och religion, PhD Diss. Gothenburg: Göteborgs universitet, 2010.

Pulkkinen, Veijo. Epäilyksen estetiikka: Tekstuaalinen variaatio ja kirjallisen teoksen identiteetti [Aesthetics of Suspicion. Textual Variation and the Identity of a Literary Work]. PhD diss., University of Oulu, 2010.

Puolakka, Kalle. Relativism and Intentionalism in Interpretation: Davidson, Hermeneutics, and Pragmatism. Lanham, MD: Lexington Books, 2011.

Rautio, Pauliina. Writing about Everyday Beauty in a Northern Village: An Argument for Diversity of Habitable Places. PhD diss., University of Oulu, 2010.

Ritið [Journal of the Center for Humanities] 1, "Museum studies/museology", edited by Sigurjón Baldur Hafsteinsson and Helga Lára Porsteinsdóttir. University of Iceland, 2010.

Ritið 2, "World cinema", edited by Björn Ægir Norðfjörð and Úlfhildur Dagsdóttir. University of Iceland, 2010.

Ritið 3, "Philosophy and literature", edited by Ásdís R. Magnúsdóttir and Björn porsteinsson. University of Iceland, 2010.

Robach, Cilla. Formens frigörelse: Konsthantverk och design under debatt $i$ 1960-talets Sverige, Konstvetenskapliga institutionen, UU. PhD Diss. Stockholm: Arvinius Förlag, 2010.

Sepänmaa, Yrjö, Virpi Kaukio, and Liisa Heikkilä-Palo, eds. Jalo kivi. Helsinki: Maahenki, 2010.

Sharma, Devika. Amerikanske fcengselsbilleder. Copenhagen: Tiderne Skifter, 2011.

Snævarr, Stefán. Metaphors, Narratives, Emotions: Their Interplay and Impact. Amsterdam and New York: Rodopi, 2010.

Stefánsdóttir, Hulda, ed. Sjónarmið: Á mótum myndlistar og heimspeki [Perspectives: at the juncture of art and philosophy]. Reykjavík: Reykjavík Art Museum, 2011.

Stenström, Thure. Ingemar Hedenius heliga rum: Sofokles - Kirkegaard - Mozart. Stockholm: Atlantis, 2011.

Sørensen, Jørgen Podemann et al., eds. Gyldendals religionshistorie: Ritualer, Mytologi, Ikonografi. Copenhagen: Gyldendal, 2011.

Sørensen, Peer E. Vor tids temperament: Studier i Herman Bangs forfatterskab. Copenhagen: Gyldendal, 2009.

Thomsen, Bodil Marie Stavning and Kristin Ørjasæter, eds. Globalizing Art: Negotiating Place, Identity and Nation in Contemporary Nordic Art. Aarhus: Aarhus University Press, 2011. 
Tvede, Øistein. Informité imaginaire et ontologique: Paul Valéry penseur, poète et captive de l'informe. Institutt for litteratur, områdestudier og europeiske språk, Universitetet i Oslo, PhD Diss., 2011.

Vanhanen, Janne. Encounters with the Virtual: The Experience of Art in Gilles Deleuze's Philosophy. PhD diss., University of Helsinki, 2010.

Wallenstein, Sven-Olov. Nihilism, Art, and Technology, Stockholm: Filosofiska Institutionen, Stockholms Universitet, 2010.

Wyller, Truls. Hva er tid? Oslo: Universitetsforlaget, 2011.

Öhrner, Annika. Barbro Östlin och New York: Konstens rum och möjligheter, Konstvetenskapliga institutionen, UU. PhD Diss. Stockholm: Makadam förlag, 2010. 